\title{
Viewpoint
}

\section{Rheumatic diseases do abound:-a midsummer night's dream}

At first irritation, then cause for thought, followed by a long look at what I try to do in my daily working life-these were the phases of my reaction to this year's Reith lectures. Though I disagreed with many of Mr Kennedy's points, it seemed to me that one of them struck home. Are we looking enough at the whole need of the patient or are we just being content with treating such an individual's problem of pain and disability in isolation? Are we as a specialty doing enough to look at the problem of the arthritic in the round, struggling to cope with his environment? Society leaves us to make the decisions about the priorities of health care, but I suspect we may content ourselves too much with thinking about our own hospital ward and clinics, and not enough, for instance, about the impact (or lack of it) the local authority is making on the comfort, convenience, and welfare of the arthritic patient in his or her own home.

Are we concerning ourselves nearly enough with the provision of facilities in the community? I wonder when was the last time we confronted the local civil servants with their duty to make sure arthritics can get in and out of offices, shops, and buses, for example.

Thomas Burke said that 'to lament the past, to conceive extravagant hopes of the future, are the common dispositions of the greatest part of mankind.' The future in the Health Service looks somewhat constrained, so we have to look very carefully at whether we are spending our present budgets wisely enough. Our local area treasurer told me recently I was responsible for spending, as a consultant, about $£ 500000$ a year. This arose during discussions over giving my department its own budget to manage, so that we are faced with the direct financial consequences of decisions of policy within the unit-a powerful means of concentrating the mind, and a salutary one. This led me to think about how I can make savings so that I can employ an extra nurse to follow the unit's patients out into their own homes and to see how they cope and perhaps try to appreciate their domestic problems more efficiently than hitherto. If I want to employ such a nurse, and think this is a reasonable priority, then I must find the money from within my own budget.

Like so many provincial units, I suppose, we have the responsibility of looking after large numbers of arthritic people but with severely limited manpower resources. It certainly teaches us to be cost effective in what we do.

I would like us to look a little harder at how we spend our research resources and time. Immunologyo is a fascinating and very valuable discipline withe which to help us to understand the disease processes we wrestle with in our everyday working life, but have we put too much emphasis on it? This is not to decry its importance, which is self evident (at least at the moment), but more a plea for a more balanced approach to our researches. Where is our chair of osteoarthritis studies-or of epidemiology, of backache studies, community care problems, or therapeutics?

Of course many rheumatologists work in these fields, but it is noticeable now at Heberden Society meetings that the emphasis of papers is on immunological studies and not so much as there should be on more clinical subjects. The reason for this is because the majority of papers submitted are of this type, not because in competition they prove to be the better papers. The inference is obvious: as rheumatologists we are not devoting enough time and thought to the other questions posed by arthritis. Goodness knows there are questions unanswered enough. 